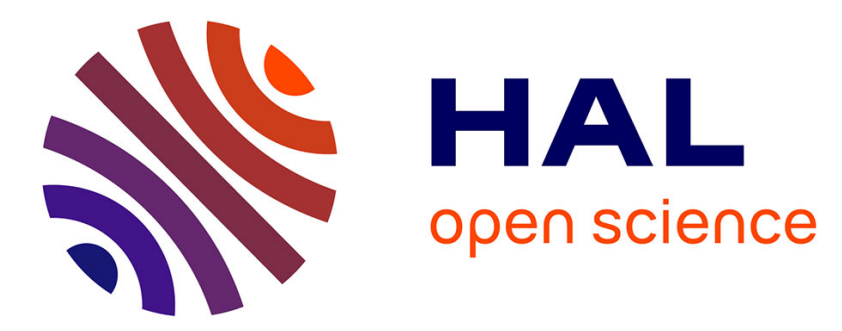

\title{
Tuning Biotic and Abiotic Calcite Growth by Stress
}

Bahareh Zareeipolgardani, Agnès Piednoir, Jean Colombani

\section{To cite this version:}

Bahareh Zareeipolgardani, Agnès Piednoir, Jean Colombani. Tuning Biotic and Abiotic Calcite Growth by Stress. Crystal Growth \& Design, 2019, 19 (10), pp.5923-5928. 10.1021/acs.cgd.9b00944 . hal-02364802

\section{HAL Id: hal-02364802 https://univ-lyon1.hal.science/hal-02364802}

Submitted on 15 Nov 2019

HAL is a multi-disciplinary open access archive for the deposit and dissemination of scientific research documents, whether they are published or not. The documents may come from teaching and research institutions in France or abroad, or from public or private research centers.
L'archive ouverte pluridisciplinaire HAL, est destinée au dépôt et à la diffusion de documents scientifiques de niveau recherche, publiés ou non, émanant des établissements d'enseignement et de recherche français ou étrangers, des laboratoires publics ou privés. 


\title{
Tuning biotic and abiotic calcite growth by stress
}

\author{
Bahareh Zareeipolgardani, Agnès Piednoir, and Jean Colombani* \\ Institut Lumière Matière; Université de Lyon; Université Claude Bernard Lyon 1; CNRS \\ UMR 5306; Domaine scientifique de la Doua, F-69622 Villeurbanne, France \\ E-mail: jean.colombani@univ-lyon1.fr
}

\begin{abstract}
During diagenesis, construction material hardening or biomeralization, the transformation of loose grains into a cohesive solid requires the crystallites to grow eventually constrained by the surrounding grains. Whereas never measured, this confinement and the associated stress is expected to influence noticeably the growth, and the final properties of the material. We report here on atomic force microscopy measurements of atomic step velocity during calcite growth, with a varying stress applied by the tip to the surface. The stress has a double influence: it both slows down the growth, and modifies the material crystalline phase. Furthermore, the addition of a small quantity of oligopeptide is shown to have no significant influence on the kinetics, but to completely cancel the phase change under stress. Our results emphasize the previously unknown role of stress on growth mechanisms and identify a new possible role of organic molecules in tuning the morphology of biomineralized materials.
\end{abstract}

\section{Introduction}

The ability to predict mineral nucleation and growth rate, and the understanding of the underlying mechanisms, have fostered recently an intense activity. Whereas new concepts 
have lately improved our comprehension, among which one can cite hydration layer disruption, ${ }^{1}$ polynuclear complex, ${ }^{2}$ amorphous precursors, ${ }^{3}$ or non-stoechiometric growth, ${ }^{4}$ and despite some successes of growth rate prediction, ${ }^{5,6}$ the basic molecular events at the heart of growth are not firmly established yet. ${ }^{7}$ Therefore we are still far from having a comprehensive view of the nucleation and growth processes. However, these phenomena involve crucial challenges in geological, biological and industrial contexts. We can cite the development of low energy consumption cements, the need of anthropogenic carbon dioxide sequestration, or the physical control on biomineralization as a promising new route for smart materials engineering. ${ }^{8}$

Calcite is a major constituent of sedimentary rocks on the Earth surface, where it forms in inorganic or biogenic conditions. ${ }^{9}$ Calcium carbonate growth from hydrated lime is also one of the oldest construction method of Man. ${ }^{10}$ During the setting process of these natural or man-made materials, the condition for loose grains to transform into a cohesive material is that growing grains end up entering into contact, and progressively stick to each other. Thus stress develops between them and growth proceeds in constrained conditions, with potential dramatic consequences on the final properties of the material. ${ }^{11,12}$ Furthermore in burial conditions in the Earth Mantle, a lithostatic pressure of up to a few GPa adds to this stress. ${ }^{13}$ As the actual contact surface area is generally much smaller than the apparent one, much higher stresses should build up. This fundamental aspect of calcite growth has so far not been addressed and the effect of stress remains unknown. Even though the consideration of the crucial importance of the confinement on calcite precipitation at the atomic scale has been demonstrated accurately, ${ }^{14}$ all remains to be done concerning the way the stress resulting from this confinement influences the phenomenon.

Biotic calcite is grown by living organisms, using numerous and complex processes among which one can cite concentration and transport of constituting ions by vesicles, ${ }^{15}$ polymorph selection by incorporation of organics ${ }^{16}$ or surface templating, ${ }^{17}$ or nanolayering by organomineral additives. ${ }^{18}$ Organics used in these processes are in turn known to strongly modify the 
response to stress of their host biomaterials, in blocking dislocation migration ${ }^{19}$ or modifying cleavage plane. ${ }^{16}$ They are therefore expected to noticeably modify the response of the material to stress during growth.

The difficulty of studying stressed calcite lies in the fact that high applied stresses are likely to exceed the mechanical strength of the material. To circumvent this issue, we have used an original method, inspired by the configuration of real contact between grains, where the stress develops mainly at asperities. We have applied on a growing surface a well defined local force with an AFM tip, playing the role of an asperity, and parallely, used this tip to image the surface.

We have observed that the stress has a huge influence on the growth because it changes both its structure and its kinetics. Indeed on one hand it slows down significantly the growth rate and on the other hand it induces a phase transition. Furthermore, the addition of an amino acid at low concentration, widespread in biomineralized tissues, whereas having no significant effect on the growth rate, cancels this phase transition, showing how biomolecules are prone to tune the influence of stress on growth.

\section{Materials and methods}

In all experiments, the ionic strength was fixed at $0.11 \mathrm{M}$ with $\mathrm{NaCl}$, the $\mathrm{pH}$ at 9.0 with $\mathrm{NaOH}(0.1 \mathrm{M})$, and the $\mathrm{Ca} / \mathrm{CO}_{3}$ activity ratio was held at 0.34 . The saturation index $\mathrm{SI}=$ $\log \left(a\left(\mathrm{Ca}^{2+}\right) a\left(\mathrm{CO}_{3}^{2-}\right) / K_{\mathrm{sp}}\right)$, with $a$ the activities and $K_{\mathrm{sp}}$ the solubility product of calcite, was calculated using the speciation freeware Phreeqc ${ }^{20}$ and controlled regularly by inductively coupled plasma mass spectrometry (ICP-MS). The supersaturation used for the chemical potential computation is defined as $\Omega=\left(a\left(\mathrm{Ca}^{2+}\right) a\left(\mathrm{CO}_{3}^{2-}\right) / K_{\mathrm{sp}}\right)^{1 / 2}$.

Among amino acids, we have selected pentaglycine, because it is already known to contribute to biomineralization. ${ }^{21}$ At $\mathrm{pH} 9.0$, at which our experiments were performed, pentaglycine is zwitterionic, with $20 \%$ of its functional groups deprotonated. 

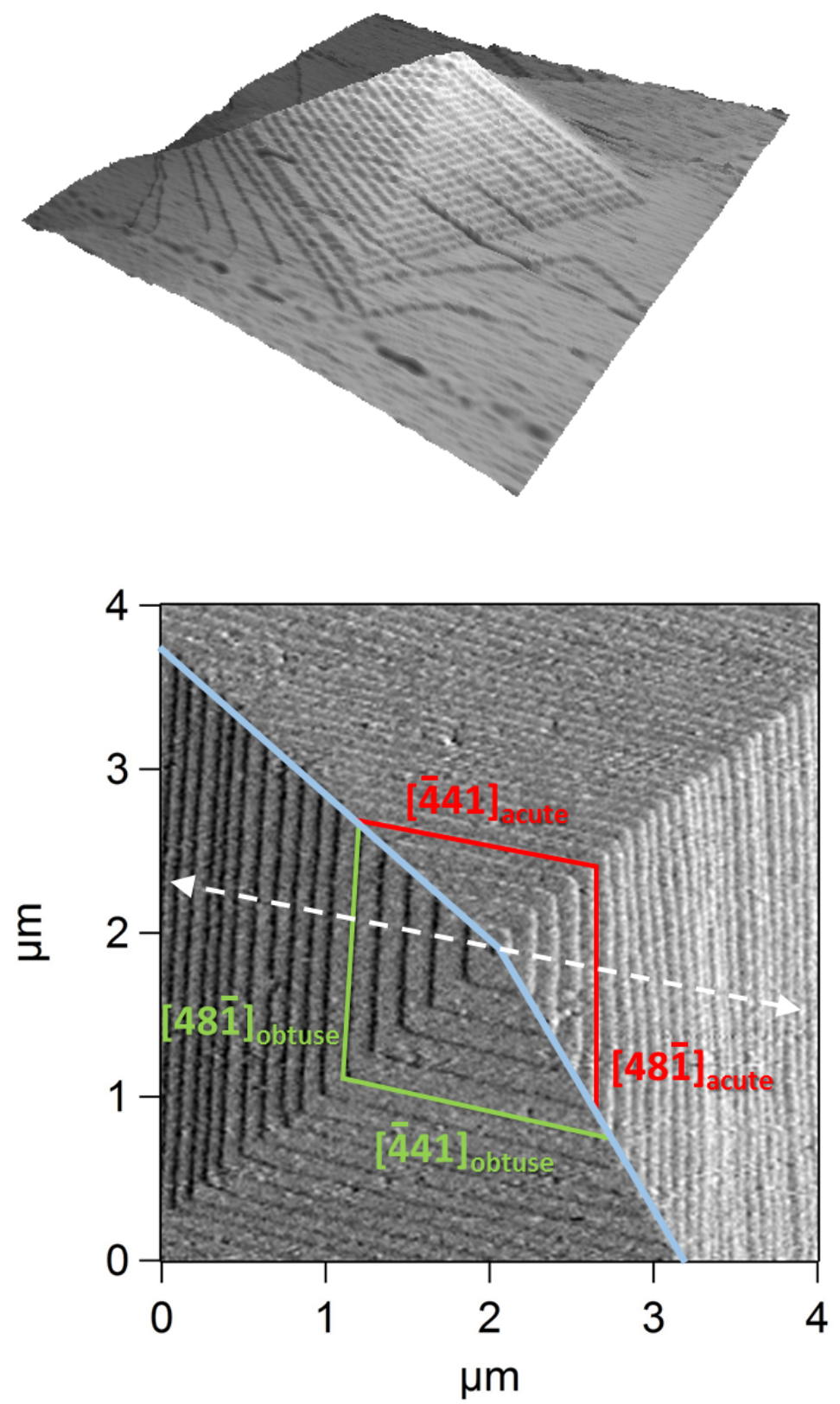

Figure 1: Top: three dimensional AFM view of a grown spiral pyramid $\sim 10 \mathrm{~nm}$ high on a calcite cleavage surface. The scanned zone is $10 \times 10 \mu \mathrm{m}^{2}$ wide. Bottom: AFM deflection mode image of the top of the pyramid. The obtuse and acute steps are shown. The angle of the two lines sharing acute and obtuse steps, passing through the apex, is non-plane, due to nonequivalent velocities of the two steps. The white arrow shows the tip path during step velocity measurements. 
The samples were made of Iceland spar from Chihuahua, Mexico, the purity of which was estimated as $99 \%$ of calcium content with inductively coupled plasma atomic emission spectroscopy (ICP-AES) and energy dispersive X-ray spectroscopy (EDX). The calcite was cleaved in air by gently scratching a scalpel along the (1014) cleavage plane to achieve a 1 to $2 \mathrm{~mm}$ thick calcite crystal with a fresh surface, which was cleaned of any dust by blowing pure nitrogen. The crystal was then mounted in a custom made flow cell.

In situ AFM imaging at $25^{\circ} \mathrm{C}$ was performed in contact mode (Digital MFP3D, Asylum Research, Oxford Instruments) during a continuous flow of supersaturated solution through a fluid cell at a constant $0.275 \mathrm{~mL} / \mathrm{min}$ flow rate, ensuring a step growth velocity independent of the flow rate. We must notice that the way the geometry of the AFM cell affects the concentration field and, accordingly, the step velocity, is still quite controversial. ${ }^{22}$ For example in the case of gypsum, computations have shown that the cell geometry can strongly influence the concentration field, ${ }^{23}$ whereas microelectrode measurements conclude to the absence of concentration gradient above the dissolving surface. ${ }^{24}$

The step movement rates were measured by aligning the scan direction so that two facing steps, one acute and one obtuse (Fig. 1) were parallel to the $Y$ scan direction and then disable this scan direction. Thereby a kymogram was obtained, with the step migration leaving a track in the $(X, t)$ plane ( $t$ the time) and the velocity being the slope of the track. ${ }^{25,26}$ With this method the scanning AFM tip has a double role: it measures the step velocity and, to achieve this goal, it applies locally a given force to the crystal.

$\mathrm{Si}_{3} \mathrm{~N}_{4}$ AFM tip cantilevers of low stiffness, with gold coating on detector side, were used to apply forces between 0 and $250 \mathrm{nN}$, and silicon tip with high stiffness were utilized to apply forces ranging from 0 to $800 \mathrm{nN}$ to the scanned surface. The overlapping range was used for double-checking. 


\section{Results}

We observe that the growth at the cleavage face (10̄14) of calcite in a flowing supersaturated solution of saturation index ranging between 0.3 and 0.65 predominantly proceeds through spiral growth, an hillock progressively forming from continuously nucleating and growing atomic steps (see Fig. 1 and video 1 in Supporting Information). The starting point of the spirals is likely to be an outcropping screw dislocation. ${ }^{27}$ This growth mechanism is characteristic of the range of low saturation indices we have investigated, ${ }^{28}$ higher indices inducing additionally island nucleation on flat terraces. ${ }^{29}$ The spiral pyramids exhibit straight edges and sharp corners with rhombohedral cross section. ${ }^{30}$ Each spreading layer is bounded by two obtuse, in the $[\overline{4} 41]_{\text {obtuse }}$ and $[48 \overline{1}]_{\text {obtuse }}$ crystallographic directions, and two acute, $[\overline{4} 41]_{\text {acute }}$ and $[48 \overline{1}]_{\text {acute, }}$ steps edges (Fig. 1).

Spiral growth can originate from individual dislocation with Burgers vector being a multiple of the lattice parameter. ${ }^{28}$ Thus we have observed double or triple spiral growth (see Fig. S1 and video 2 in Supporting Information) but we have focused here only on the step velocity of single spiral growth.

The two classes of steps are seen to migrate at different velocities (see Fig. 2 and Fig. S2 in Supporting Information), which induces a non-plane angle between facing edges of the pyramids (see Fig. 1). This discrepancy results from the geometric difference between the two classes of steps, leading in different rates of kink site nucleation at the step edge and incorporation of ions at these kink sites during growth. Consequently, This discrepancy is known to be highly dependent on the chemical conditions, especially on the $\left[\mathrm{Ca}^{2+}\right] /\left[\mathrm{CO}_{3}^{2-}\right]$ ratio. Consistent with former studies, obtuse steps are seen to migrate faster in the chemical conditions of our solution. ${ }^{31-33}$

As expected, step velocities increase when the saturation index raises, the driving force of growth being thus enhanced. But what had never been observed is that these velocities depend on the force the steps are submitted to as well (Fig. 2 and S2 in Supporting Information). Furthermore the step velocities display unexpectedly a non-monotonous evolution 
with the applied force, with an initial decay, followed by a kind of jump, and then a resumption of the decrease. So two distinct regimes appear, separated by an abrupt transition.

To evaluate the influence of organic molecules on biomineralization, we have tested the modification of growth under stress in presence of an oligopetpide. The addition of $82 \mu \mathrm{M}$ of pentaglycine in the solution is seen to provoke a radical change of the step velocity behavior. Indeed the jump around $200 \mathrm{nN}$ disappears completely and the velocity exhibits now a smooth and continuous decrease up to $700 \mathrm{nN}$ (Fig. 3).

As the steps move slower in the vicinity of the tip than elsewhere on the surface, the tip is expected to leave a trace of its passage. But the steps relax toward a straight shape as soon as the tip stops scanning back and forth along the line. Therefore this trace is difficult to observe. Nevertheless an example is shown in Fig. 4.

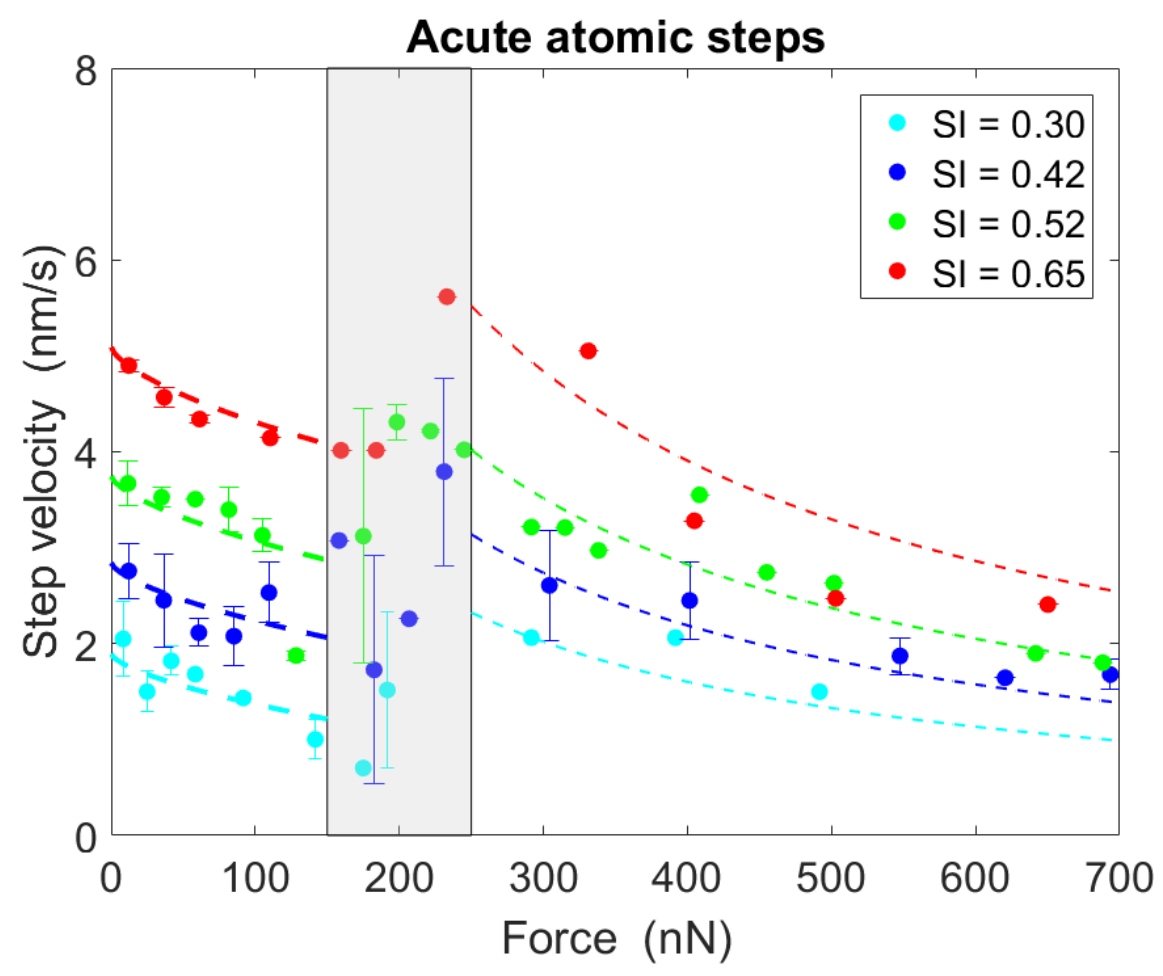

Figure 2: Evolution of the acute step velocity as a function of the force applied by the scanning AFM tip on a calcite cleavage surface during growth in a solution of saturation index SI. The grey box marks the probable phase transition zone between calcite I and calcite III. The dashed curves are fits of the experimental data with Eq. 1. 


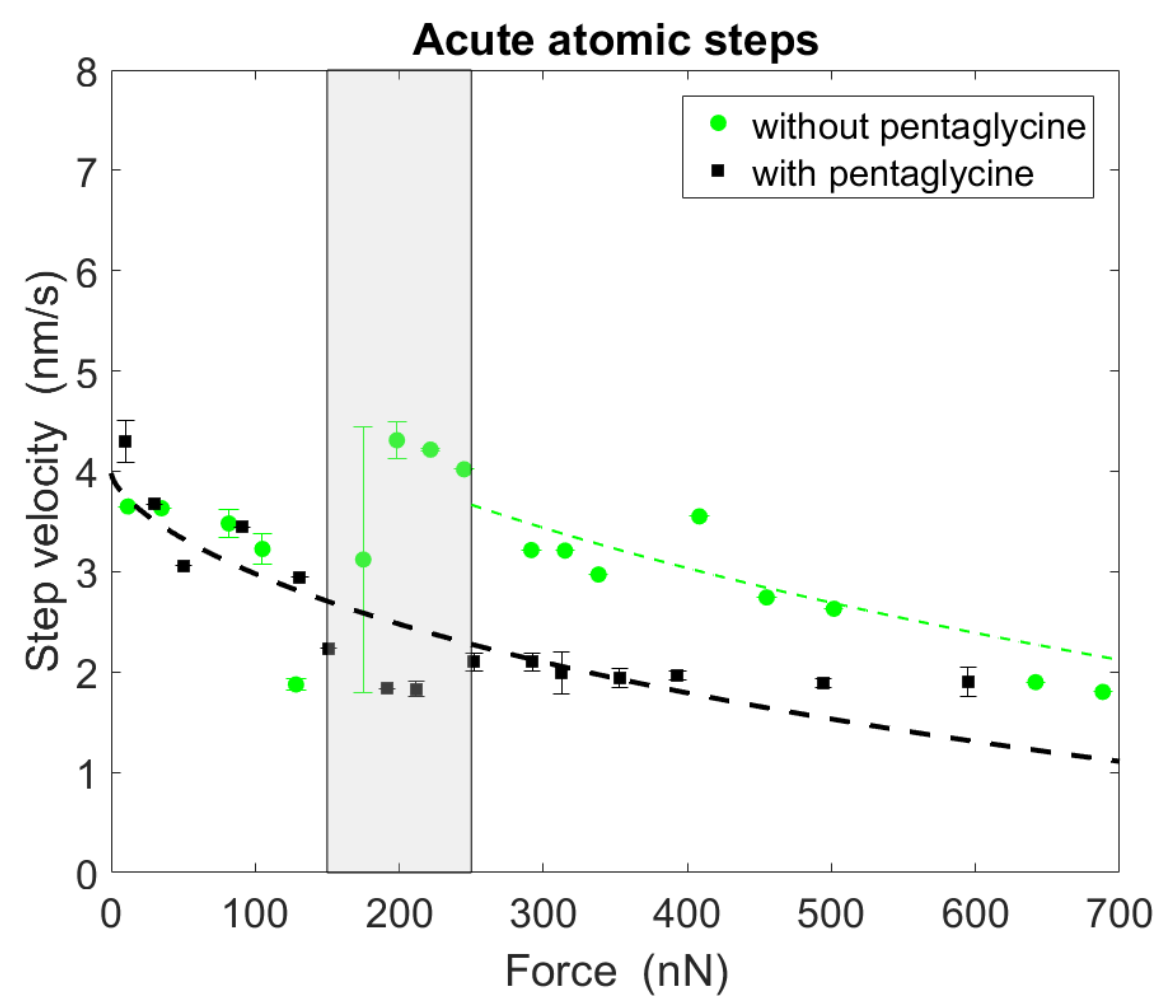

Figure 3: Evolution of the acute step velocity as a function of the force applied by the AFM tip on a calcite cleavage surface during growth in a solution of saturation index SI $=0.55$ with and without $82 \mu \mathrm{M}$ of pentaglycine. The dashed curves are fits of the experimental data with Eq. 1. 


\section{Discussion}

For forces below $F \sim 200 \mathrm{nN}$, the step velocity in all conditions exhibits a continuous and monotonic decrease (Fig. 2 and S2 in Supporting Information). This decrease cannot stem from the mere limited access of the solute to the growing step in the vicinity of the tip because in this case the reduced velocity would not depend on the applied force. Therefore we interpret this trend as a consequence of the change of Gibbs free energy of the mineral induced by the elastic strain caused by the tip. Indeed, the step motion driving force is the chemical potential difference between the solid and liquid. The supersaturation of the solution induces an increase of the chemical potential of the liquid, that triggers the nucleation and growth. The elastic energy stored by the solid with the passage of the tip then enhances the chemical potential of the solid, which in turn reduces the disequilibrium, thus slowing down the growth. This inhibiting effect of stress is reminiscent of the dissolution of crystals in supersaturated solutions, due to the strain induced by some adsorbed inhibitor. ${ }^{34}$ This effect is opposite to the case of dissolution, where the elastic energy amplifies the disequilibrium. ${ }^{26}$

The velocity $v$ dependence on the solid-liquid Gibbs free energy difference $\Delta G$ writes $v=v_{0}(\exp (\Delta G /(R T))-1)$, where $v_{0}$ is the velocity at vanishing driving force, $R$ the gas constant and $T$ the temperature. ${ }^{30}$ The driving force contains both the chemical and mechanical contributions: $\Delta G=R T \ln \Omega+\delta U_{\mathrm{e}}$, where $\Omega$ is the solution supersaturation and $\delta U_{\mathrm{e}}$ the molar elastic energy of the solid. ${ }^{35}$ This last quantity can be obtained via $\delta U_{\mathrm{e}}=\sigma^{2} \bar{V} /(2 E)$, with $\bar{V}$ and $E$ the molar volume and Young's modulus of calcite $(\bar{V}=$ $37 \times 10^{-5} \mathrm{~m}^{3} / \mathrm{mol}$ and $\left.E=86 \mathrm{GPa}\right)$ and $\sigma$ the applied stress.

As the space between the pressing tip and the surface is inaccessible to the solute, growth should proceed at the periphery of the tip. So we approximate the tip-surface interaction by a Hertzian contact and take $\sigma$ as the tensile stress at the contact line.

Consequently the step velocity should follow the following relationship:

$$
v=v_{0}\left(\Omega \exp \left(-\alpha \sigma^{2} \bar{V} /(2 E R T)\right)-1\right)
$$


with $\alpha$ a geometric factor linked to the range of the elastic field around the tip-surface contact. The experimental data are satisfactorily fitted by this thermodynamic law (see Fig. 2, 3 and $\mathrm{S} 2$ in Supporting Information).

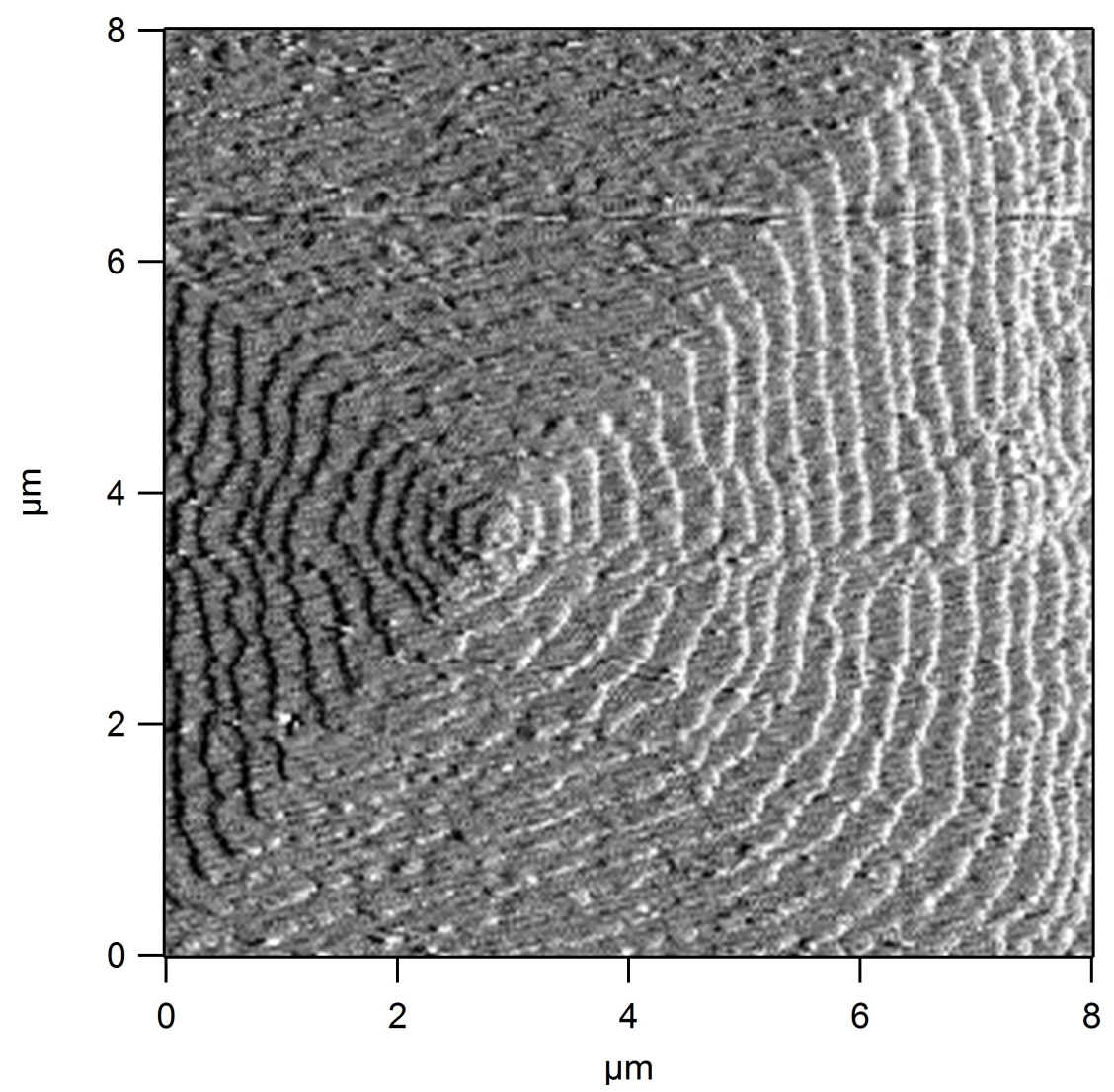

Figure 4: Hillock on a growing calcite surface imaged by AFM with a low applied force (15 $\mathrm{nN})$, after the velocity of the steps has been measured along a single line at high force (300 $\mathrm{nN}$ ). The vanishing trace left by the passage of the tip is observable on the right of the hillock apex.

An alternative explanation of the influence of the stress is to consider that this one does not reduce the attachment rate of the solute to the step, which Eq. 1 implicitly states, but increase the detachment rate, the balance of which determines the net growth rate. ${ }^{36}$ Fig. S3 and S4 in Supporting Information show a fit of the experimental data with the corresponding law. This one is very similar to the fit of Eq. 1 and it is not possible to discriminate between both processes.

No abrupt change is expected from this theory. The origin of the break around $200 \mathrm{nN}$ is 
accordingly to be searched for elsewhere. Using again Hertzian mechanics, the corresponding maximal pressure experienced by the surface under the tip for this force value is $\sim 2 \mathrm{GPa}$. Actually, this value is well-known to be the one where calcite exhibits a phase transition between the calcite I and calcite III polymorph, with a transitory calcite II phase. ${ }^{37}$ So we ascribe the change of behavior of the growing surface to a phase change from calcite I to calcite III triggered in the vicinity of the tip by the applied pressure. ${ }^{38}$ This possible AFMinduced calcite phase transition had been evoked decades ago but never checked so far. ${ }^{39}$ It originates in a rotation of the carbonate group in the crystalline cell. The determination of the bulk calcite III lattice is a challenging issue for years. ${ }^{13}$ The interest in this polymorph has raised lately due to the discovery of metastable calcite III formed near the surface. ${ }^{40}$ The mechanism of growth under pressure that we evidence here may contribute to explain the presence of such a high pressure polymorph in near-surface sediments.

In the high force regime, the velocity decrease should again originate in the equilibrium displacement induced by the elastic energy provided by the tip pressure. But as the calcite III lattice, and a fortiori its mechanical properties, are still debated, we have fitted the experimental data with the same functional law only as a guide to the eye (see Fig. 2, 3 and S2 in Supporting Information).

The Bravais lattice of calcite III is different from the one of calcite I, and the moving steps likewise. Their crystallographic directions are unknown, but we observe that their mobility is completely modified, the ex-obtuse steps moving now slower than the ex-acute steps whereas the obtuse steps were faster than the acute ones in the low force regime.

We recall that the two observed growing lattices of calcite are equilibrium phases, therefore once high forces are no more applied to the surface, calcite III transforms progressively into calcite I. A striking example of this spontaneous relaxation of the surface from its high pressure to its low pressure form is shown in videos 3 and 4 in Supporting Information.

During dissolution, from a given threshold on, the application of a high force by the scanning AFM tip has been seen to induce a damaging of a gypsum or calcite surface, 
creating kink sites in the migrating steps. ${ }^{26,41}$ But the functional dependence of the step speed on the applied force was observed to be completely different from a pressure solution law, following instead a much faster Arrhenius increase. With this in mind, we have ruled out such a corrosive wear here because for two reasons. First the $v(F)$ curve should not follow a pressure growth law like Eq. 1. Furthermore the increase in the number of kink sites with the damaging should induce an increase, not a decrease, of the velocity with the applied force. Secondly no abrupt jump in the $v(F)$ should be observed.

In the low force regime, no detectable change of step velocity by the pentaglycine addition is observed (Fig. 3). This absence of amino acid effect is in line with the weak modification of calcite growth rate by pentaglycine in bulk experiments in this concentration range, ${ }^{21} \mathrm{a}$ common characteristic of peptides. ${ }^{42}$ This absence of modification may derive from the fact that the change of calcite rigidity due to its occlusion in the crystal is negligible, as in the case of aspartate. ${ }^{43}$

Even though the mechanisms of modification of calcite mechanical properties by incorporated amino acids has progressed lately, ${ }^{19}$ the interpretation of the way pentaglycine molecules mitigate the action of stress in the high force regime is delicate. The interpretation of the way pentaglycine molecules mitigate the action of stress in the high force regime is more delicate. Even though the mechanisms of modification of calcite mechanical properties by incorporated amino acids has progressed lately, ${ }^{19}$ the cancellation or postponement of a pressure-induced phase transition is not easily explained. We propose that the binding of pentaglycine to the surface carbonate groups ${ }^{21}$ prevents their rotation and thus, despite its small concentration, impedes the structure change of the crystal. Regarding the low concentration of amino acid in solution, the ability of the resulting small quantity of adsorbed molecules to control the high pressure phase diagram of calcite is remarkable. 


\section{Conclusion}

We have shown that a stress imposed to a growing calcite crystal, an unavoidable step in the formation of a cohesive material, as much limestone as shells, has two visible effects: kinetically it slows down noticeably the mineral growth, and structurally it changes its crystalline lattice, these two feature having a broad potential impact on the final material properties. Furthermore, the presence of a prevalent amino acid in the solution, has no significant repercussion on the kinetics, but a huge influence on the structure, canceling the pressure-induced phase transition of calcite, thus selecting the growing polymorph. This process should depend on the nature of amino acid, concentration, and mineral type, but adds to the collection of mechanisms by which organics tune biomineralization.

\section{Acknowledgement}

This project has received funding from the European Union Horizon 2020 research and innovation program under the Marie Sklodowska-Curie grant agreement no. 642976-NanoHeal Project. The results of this paper reflect only the author's view and the Commission is not responsible for any use that may be made of the information it contains. The authors thank Sylvie Le Floch, Olivier Pierre-Louis, Nicholas Harrison, Fernando Bresme, Dag Kristian Dysthe, Nico Bové, David Carrasco de Busturia, Goran Svaland, Boaz Prokroy and Fabio Reiss for stimulating discussions.

\section{References}

(1) Stipp, S. L.; Hochella, M. F. Structure and Bonding Environments at the Calcite Surface as Observed with X-Ray Photoelectron-Spectroscopy (XPS) and Low-Energy ElectronDiffraction (LEED). Geochim. Cosmochim. Acta 1991, 55, 1723-1736. 
(2) Andersson, M.; Dobberschtz, S.; Sand, K.; Tobler, D.; Yoreo, J. D.; Stipp, S. A Microkinetic Model of Calcite Step Growth. Angew. Chem. 2016, 128, 1-6.

(3) Van Driessche, A. E. S.; Benning, L. G.; Rodriguez-Blanco, J. D.; Ossorio, M.; Bots, P.; García-Ruiz, J. M. The Role and Implications of Bassanite as a Stable Precursor Phase to Gypsum Precipitation. Science 2012, 336, 69-72.

(4) Perdikouri, C.; Putnis, C. V.; Kasioptas, A.; Putnis, A. An atomic force microscopy study of the growth of a calcite surface as a function of calcium/total carbonate concentration ratio in solution at constant supersaturation. Crystal Growth Des. 2009, 9, $4344-4350$.

(5) Bracco, J. N.; Stack, A. G.; ; Steefel, C. I. Upscaling Calcite Growth Rates from the Mesoscale to the Macroscale. Environ. Sci. Technol. 2013, 47, 7555-7562.

(6) Wothers, M.; Tommaso, D. D.; Du, Z.; de Leeuw, N. Variations in calcite growth kinetics with surface topography: molecular dynamics simulations and process-based growth kinetics modelling. CrystEngComm 2013, 15, 5506-5514.

(7) de la Pierre, M.; Raiteri, P.; Stack, A.; Gale, J. Uncovering the Atomistic Mechanism for Calcite Step Growth. Angew. Chem. Int. Ed. 2017, 56, 8464-8467.

(8) Bouville, F.; Maire, E.; Meille, S.; de Moortèle, B. V.; Stevenson, A.; Deville, S. Strong, tough and stiff bioinspired ceramics from brittle constituents. Nature Mat. 2014, 13, $508-514$.

(9) Larsen, K.; Bechgaard, K.; Stipp, S. L. S. The effect of the $\mathrm{Ca}^{2+}$ to $\mathrm{CO}_{3}^{2-}$ activity ratio on spiral growth at the calcite $\{10 \overline{1} 4\}$ surface. Geochim. Cosmochim. Acta 2010, 74, 2099-2109.

(10) Vitruvius, The ten books of architecture English - translation by M. H. Morgan; Dover: New York, 1914. 
(11) Wang, Y.-W.; Christenson, H. K.; Meldrum, F. C. Confinement Leads to Control over Calcium Sulfate Polymorph. Adv. Funct. Mater. 2013, 23, 5615-5623.

(12) Kohler, F.; Gagliardi, L.; Pierre-Louis, O.; Dysthe, D. Cavity Formation in Confined Growing Crystals. Phys. Rev. Lett. 2018, 121, 096101.

(13) Merlini, M.; Hanfland, M.; Crichton, W. A. $\mathrm{CaCO}_{3}-\mathrm{III}$ and $\mathrm{CaCO}_{3}$-VI, high-pressure polymorphs of calcite: Possible host structures for carbon in the Earth's mantle. Earth Planet. Sci. Lett. 2012, 333-334, 265-271.

(14) Diao, Y.; Espinoza-Marzal, R. Molecular insight into the nanoconfined calcitesolution interface. Proc. Natl. Acad. Sci. USA 2016, 113, 12047-12052.

(15) S.Weiner,; Addadi, L. Crystallization Pathways in Biomineralization. Annu Rev. Mater. Res. 2011, 41, 21.

(16) Weber, E.; Pokroy, B. Intracrystalline inclusions within single crystalline hosts: from biomineralization to bio-inspired crystal growth. CrystEngComm 2015, 17, 5873.

(17) Damle, C.; Kumar, A.; Sainkar, S.; Bhagawat, M.; Sastry, M. Growth of Calcium Carbonate Crystals within Fatty Acid Bilayer Stacks. Langmuir 2002, 18, 6075.

(18) Ihli, J.; Clark, J.; Kanwal, N.; Kim, Y.; Holden, M.; Harder, R.; Tang, C.; Ashbrook, S.; Robinson, I.; Meldrum, F. Visualization of the effect of additives on the nanostructures of individual bio-inspired calcite crystals. Chem. Sci. 2019,

(19) Kim, Y.-Y.; Carloni, J. D.; Demarchi, B.; Sparks, D.; Reid, D. G.; Kunitake, M. E.; Tang, C. C.; Duer, M. J.; Freeman, C. L.; Pokroy, B.; Penkman, K.; Harding, J. H.; Estroff, L. A.; Baker, S. P.; Meldrum, F. C. Tuning hardness in calcite by incorporation of amino acids. Nature Mat. 2016, 15, 903-912. 
(20) PHREEQC interactive, version 3.4.0-12927, a computer program for speciation, batchreaction, one-dimensional transport and inverse geochemical calculations. U.S. Geological Survey, https://water.usgs.gov/software/.

(21) Montanari, G.; Lakshtanov, L.; Tobler, D.; Dideriksen, K.; Dalby, K. N.; Bovet, N.; Stipp, S. Effect of Aspartic Acid and Glycine on Calcite Growth. Crystal Growth Des. 2016, 16, 4813-4821.

(22) Gasperino, D.; Yeckel, A.; Olmsted, B.; Ward, M.; Derby, J. Mass transfer limitations at Crystallizing interfaces in an atomic force microscopy fluid cell: A finite element analysis. Langmuir 2006, 22, 6578-6586.

(23) Peruffo, M.; Mbogoro, M.; Adobes-Vidal, M.; Unwin, P. Importance of mass transport and spatially heterogeneous flux processes for in situ atomic force microscopy measurements of crystal growth and dissolution kinetics. J. Phys. Chem. C 2016, 120, $12100-12112$.

(24) Burgos-Cara, A.; Putnis, C.; Rodriguez-Navarro, C.; Ruiz-Agudo, E. Hydration effects on gypsum dissolution revealed by in situ nanoscale atomic force microscopy observations. Geochim. Cosmochim. Acta 2016, 179, 110-122.

(25) Fan, C.; Teng, H. Surface behavior of gypsum during dissolution. Chem. Geol. 2007, $245,242$.

(26) Zareeipolgardani, B.; Piednoir, A.; Colombani, J. Gypsum Dissolution Rate from Atomic Step Kinetics. Journal of Physical Chemistry C 2017, 121, 9325-9330.

(27) Clark, J.; Ihli, J.; Schenk, A.; Kim, Y.; Kulak, A.; Campbell, J.; Nisbet, G.; Meldrum, F.; Robinson, I. Three-dimensional imaging of dislocation propagation during crystal growth and dissolution. Nature Mater. 2015, 14, 780-784. 
(28) Teng, H. H.; ; Dove, P. M.; De Yoreo, J. J. Kinetics of calcite growth : Surface processes and relationships to macroscopic rate laws. Geochim. Cosmochim. Acta 2000, 64, 22552266.

(29) Dove, P. M.; Hochella, M. F. Calcite precipitation mechanisms and inhibition by orthophosphate: In situ observations by Scanning Force Microscopy. Geochim. Cosmochim. Acta 1993, 57, 705-714.

(30) Teng, H. H.; Dove, P. M.; Orme, C. A.; De Yoreo, J. J. Thermodynamics of calcite growth: Baseline for understanding biomineral formation. Science 1998, 282, 724-727.

(31) Stack, A.; Grantham, M. Growth Rate of Calcite Steps As a Function of Aqueous Calcium-to-Carbonate Ratio: Independent Attachment and Detachment of Calcium and Carbonate Ions. Crystal Growth Des. 2010, 10, 1409-1413.

(32) Hong, M.; Teng, H. H. Implications of solution chemistry effects: Direction-specific restraints on the step kinetics of calcite growth. Geochim. Cosmochim. Acta 2014, $141,228-239$.

(33) Sand, K. K.; Tobler, D. J.; Dobberschütz, S.; Larsen, K. K.; Makovicky, E.; Andersson, M. P.; Wolthers, M.; Stipp, S. L. S. Calcite Growth Kinetics: Dependence on Saturation Index, $\mathrm{Ca}^{2+}: \mathrm{CO}_{3}^{2-}$ Activity Ratio, and Surface Atomic Structure. Crystal Growth Des. 2016, 16, 3602-3612.

(34) Chung, J.; Granja, I.; Taylor, M.; Mpourmpakis, G.; Asplin, J.; Rimer, J. Molecular modifiers reveal a mechanism of pathological crystal growth inhibition. Nature 2016, $536,446-450$.

(35) Pachon-Rodriguez, E.; Piednoir, A.; Colombani, J. Pressure solution at the molecular scale. Phys. Rev. Lett. 2011, 10\%, 146102. 
(36) Yoreo, J. D.; Zepeda-Ruiz, L.; Friddle, R.; Qiu, S.; Wasylenki, L. E.; Chernov, A.; Gilmer, G.; Dove, P. Rethinking Classical Crystal Growth Models through Molecular Scale Insights: Consequences of Kink-Limited Kinetics. Crystal Growth Des. 2009, 9, $5135-5144$.

(37) Suito, K.; Namba, J.; Horikawa, T.; Taniguchi, Y.; Sakurai, N.; Kobayashi, M.; Onodera, A.; Shimomura, O.; Kikegawa, T. Phase relations of $\mathrm{CaCO}_{3}$ at high pressure and high temperature. Am. Mineral. 2001, 86, 997-1002.

(38) We would like to stress on the fact that the measurements between 150 and $250 \mathrm{nN}$ are delicate, leading to unstable values. Therefore we do not claim that velocities in this range are representative of calcite II, the existence range of this polymorph being particularly tiny.

(39) Stipp, S.; Eggleston, C.; Nielsen, B. Calcite surface structure observed at microtopographic and molecular scales with atomic force microscopy (AFM). Geochim. Cosmochim. Acta 1994, 58, 3023-3033.

(40) Schaebitz, M.; Wirth, R.; Janssen, C.; Dresen, G. First evidence of $\mathrm{CaCO}_{3}-\mathrm{III}$ and $\mathrm{CaCO}_{3}$-IIIb high-pressure polymorphs of calcite: Authigenically formed in near surface sediments. Am. Mineral. 2015, 100, 1230.

(41) Park, N.; Kim, M.; Langford, S.; Dickinson, J. Atomic layer wear of single-crystal calcite in aqueous solution scanning force microscopy. J. Applied Phys. 1996, 80, 2680.

(42) Elhadj, S.; De Yoreo, J. J.; Hoyer, J. R.; Dove, P. M. Role of molecular charge and hydrophilicity in regulating the kinetics of crystal growth. Proc. Natl. Acad. Sci. USA 2006, 103, 19237-19242.

(43) Côté, A.; Darkins, R.; Dufy, D. Deformation twinning and the role of amino acids and magnesium in calcite hardness from molecular simulation. PCCP 2015, 17, 2017820184. 


\section{Graphical TOC Entry}

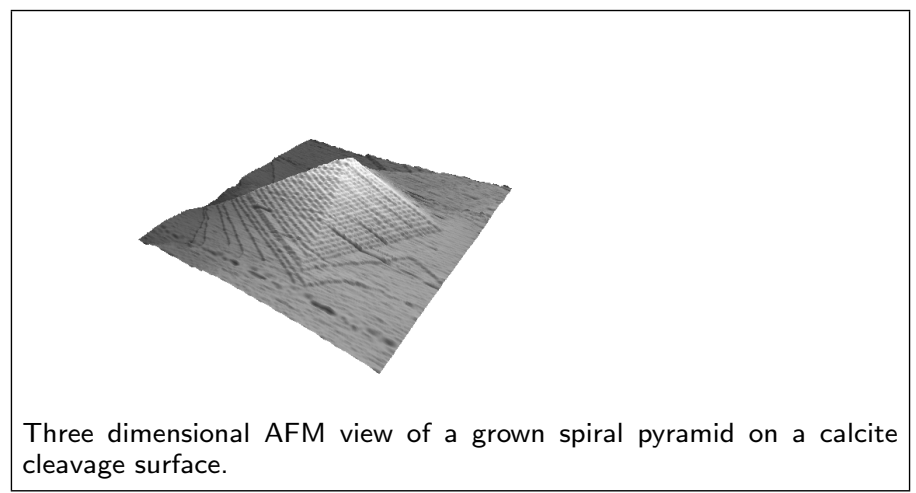

